\title{
One year of COVID-19 pandemic: what we Radiologists have learned about imaging
}

\section{Ein Jahr COVID-19-Pandemie: Was wir Radiologen über die Bildgebung gelernt haben}

Authors

Alexander Gross D, Thomas Albrecht

Affiliation

Radiology and Interventional Therapy, Vivantes-Klinikum Neukölln, Berlin, Germany

Key words

COVID-19, COVID-19 pneumonia, SARS-CoV-2, CO-RADS, extrapulmonary manifestations, pneumonia

received 02.03.2021

accepted 11.05.2021

published online 14.10.2021

Bibliography

Fortschr Röntgenstr 2022; 194: 141-151

DOI 10.1055/a-1522-3155

ISSN 1438-9029

(C) 2021. Thieme. All rights reserved.

Georg Thieme Verlag KG, Rüdigerstraße 14,

70469 Stuttgart, Germany

Correspondence

Dr. Alexander Gross

Radiology and Interventional Therapy, Vivantes-Klinikum Neukölln, Rudower Straße 48, 12351 Berlin, Germany

Tel.: +493013014-2046

alexander.gross@vivantes.de

\section{ABSTRACT}

Background Since its outbreak in December 2019, Severe Acute Respiratory Syndrome Coronavirus 2 (SARS-CoV-2) has infected more than 151 million people worldwide. More than 3.1 million have died from Coronavirus Disease 2019 (COVID-19), the illness caused by SARS-CoV-2. The virus affects mainly the upper respiratory tract and the lungs causing pneumonias of varying severity. Moreover, via direct and indirect pathogenetic mechanisms, SARS-CoV-2 may lead to a variety of extrapulmonary as well as vascular manifestations. Methods Based on a systematic literature search via PubMed, original research articles, meta-analyses, reviews, and case reports representing the current scientific knowledge regarding diagnostic imaging of COVID-19 were selected. Focusing on the imaging appearance of pulmonary and extrapulmonary manifestations as well as indications for imaging, these data were summarized in the present review article and correlated with basic pathophysiologic mechanisms. Results and Conclusion Typical signs of COVID-19 pneumonia are multifocal, mostly bilateral, rounded, polycyclic or geographic ground-glass opacities and/or consolidations with mainly peripheral distribution. In severe cases, peribronchovascular lung zones are affected as well. Other typical signs are the "crazy paving" pattern and the halo and reversed halo (the latter two being less common). Venous thromboembolism (and pulmonary embolism in particular) is the most frequent vascular complication of COVID-19. However, arterial thromboembolic events like ischemic strokes, myocardial infarctions, and systemic arterial emboli also occur at higher rates. The most frequent extrapulmonary organ manifestations of COVID-19 affect the central nervous system, the heart, the hepatobiliary system, and the gastrointestinal tract. Usually, they can be visualized in imaging studies as well. The most important imaging modality for COVID-19 is chest CT. Its main purpose is not to make the primary diagnosis, but to differentiate COVID-19 from other (pulmonary) pathologies, to estimate disease severity, and to detect concomitant diseases and complications.

\section{Key Points:}

- Typical signs of COVID-19 pneumonia are multifocal, mostly peripheral ground-glass opacities/consolidations.

- Imaging facilitates differential diagnosis, estimation of disease severity, and detection of complications.

- Venous thromboembolism (especially pulmonary embolism) is the predominant vascular complication of COVID-19.

- Arterial thromboembolism (e. g., ischemic strokes, myocardial infarctions) occurs more frequently as well.

- The most common extrapulmonary manifestations affect the brain, heart, hepatobiliary system, and gastrointestinal system.

\section{Citation Format}

- Gross A, Albrecht T. One year of COVID-19 pandemic: what we Radiologists have learned about imaging. Fortschr Röntgenstr 2022; 194: 141-151 


\section{ZUSAMMENFASSUNG}

Hintergrund Seit seinem Ausbruch im Dezember 2019 haben sich weltweit mehr als 151 Millionen Menschen mit Severe Acute Respiratory Syndrome Coronavirus 2 (SARSCoV-2) infiziert. Mehr als 3,1 Millionen Menschen starben an Coronavirus Disease 2019 (COVID-19), der durch das Virus ausgelösten Erkrankung. Hauptmanifestationsort ist neben den oberen Atemwegen die Lunge, wo es zu Pneumonien unterschiedlichen Schweregrades kommt. Darüber hinaus führt SARS-CoV-2 über direkte wie auch indirekte pathogenetische Mechanismen zu verschiedensten extrapulmonalen und vaskulären Manifestationen.

Methode Basierend auf einer systematischen Literaturrecherche mittels PubMed wurden Originalarbeiten, Metaanalysen, Übersichtsartikel und Fallberichte ausgewählt, die den aktuellen Wissensstand zur Bildgebung von COVID-19, insbesondere zum Erscheinungsbild pulmonaler wie extrapulmonaler Manifestationen sowie zur Indikation bildgebender Untersuchungen, wiedergeben. Diese Informationen wurden in der vorliegenden Übersichtsarbeit zusammengefasst und in grundlegende pathophysiologische Zusammenhänge eingeordnet.
Ergebnisse und Schlussfolgerungen Typische Zeichen einer COVID-19-Pneumonie sind multifokale, meist bilaterale, rundliche bzw. polyzyklische, teilweise auch landkartenartig konfluierende Milchglasareale und/oder Konsolidierungen in vorwiegend peripherer Verteilung; in schwereren Fällen sind zusätzlich auch peribronchovaskuläre Lungenabschnitte betroffen. Weitere typische Zeichen sind ein „Crazy Paving“Muster, seltener auch ein Halo oder Reversed Halo. Venöse Thromboembolien (u.a. Lungenarterienembolien) sind die häufigsten vaskulären Komplikationen von COVID-19, aber auch arterielle thromboembolische Ereignisse wie ischämische Schlaganfälle, Myokardinfarkte und systemische arterielle Embolien treten vermehrt auf. Die häufigsten extrapulmonalen Organmanifestationen von COVID-19 betreffen das Gehirn, das Herz, das hepatobiliäre System sowie den Gastrointestinaltrakt und sind häufig ebenfalls bildmorphologisch zu erkennen. Die größte Rolle bei der bildgebenden Diagnostik von COVID-19 spielt das Thorax-CT. Sein Wert liegt weniger in der primären Diagnosestellung als in der differenzialdiagnostischen Abgrenzung, Einschätzung des Schweregrades sowie Detektion von Begleiterkrankungen und Komplikationen.

\section{Introduction}

More than one year after the identification of the first case in Germany on 1/28/2020, COVID-19 (coronavirus disease 2019) is more relevant than ever. Since the outbreak of the disease in Wuhan (Hubei province, China) in December 2019, SARS-CoV-2 (Severe Acute Respiratory Syndrome Coronavirus 2), the pathogen causing COVID-19, has infected over 151 million people worldwide (as of 5/2/2021). Over 3.1 million have died of or with the disease [1]. More than 3.4 million infections and over 83000 deaths have been recorded in Germany (as of 5/2/2021). $88 \%$ of those who died were over the age of 70 [2]. Over 129000 medical articles on a wide range of aspects of the disease (including radiology), (PubMed search for "COVID-19" on 5/2/2021) have been published. In addition to the dominant pulmonary changes, systemic complications and manifestations in various other organ systems have increasingly become the focus of scientific interest.

\section{Pathophysiology and symptoms}

SARS-CoV-2 is an enveloped single-stranded (positive-sense) RNA virus that is primarily transmitted on an airborne-basis by inhaling viral particles emitted during breathing, coughing, and speaking; to a lesser degree it is transmitted by direct contact $[3,4]$. The most common symptoms are fever (80.4\%), cough (63.1\%), fatigue (46\%), expectoration (41.8\%), anorexia (38.8\%), tightness in the chest $(35.7 \%)$, shortness of breath (35\%), dyspnea (33.9\%), and muscle soreness (33\%) [5]. Loss of taste and smell has also been frequently described [6]. In addition to the upper respiratory tract, the virus mainly affects the lungs, with pneumonia requiring inpatient care being seen in approximately $2-3 \%$ of those infected [7, 8]. This organotropism can be explained by the high expression of the angiotensin-converting enzyme 2 (ACE2) receptor on the alveolar epithelial cells: The cellular serine protease TMPRSS and other proteases prime the spike protein of SARS-CoV-2, which binds to the ACE2 receptor and enters the host cells [9]. In addition to the lung, other organ systems are affected to varying degrees of frequency and severity, including the vascular system, the heart, the nervous system, the gastrointestinal tract, the hepatobiliary system, and the kidneys [9]. Some of these disease manifestations can be attributed to direct viral toxicity: Viral RNA as well as a co-expression of ACE2 and TMPRSS2 were detected in the indicated organs [9]. Damage to endothelial cells with resulting inflammation and formation of a prothrombotic milieu seems to be another important component in the pathogenesis of COVID-19. The expression of ACE2 has been detected in arterial and venous endothelial cells of various organs, and histopathological studies have shown microthrombi in small vessels of the lung among other organs [9, 10]. Dysregulation of the immune response with a cytokine storm is a further pathophysiological characteristic of severe COVID-19 [9]. Not least, a disruption of the renin-angiotensin-aldosterone system plays a pathogenetic role [9]. The role of these individual mechanisms in the overall pathophysiology of COVID-19 has not yet been sufficiently clarified. In severe cases, general pathophysiological processes of systemic infection and inflammation including changes in the coagulation system are also seen [9]. 

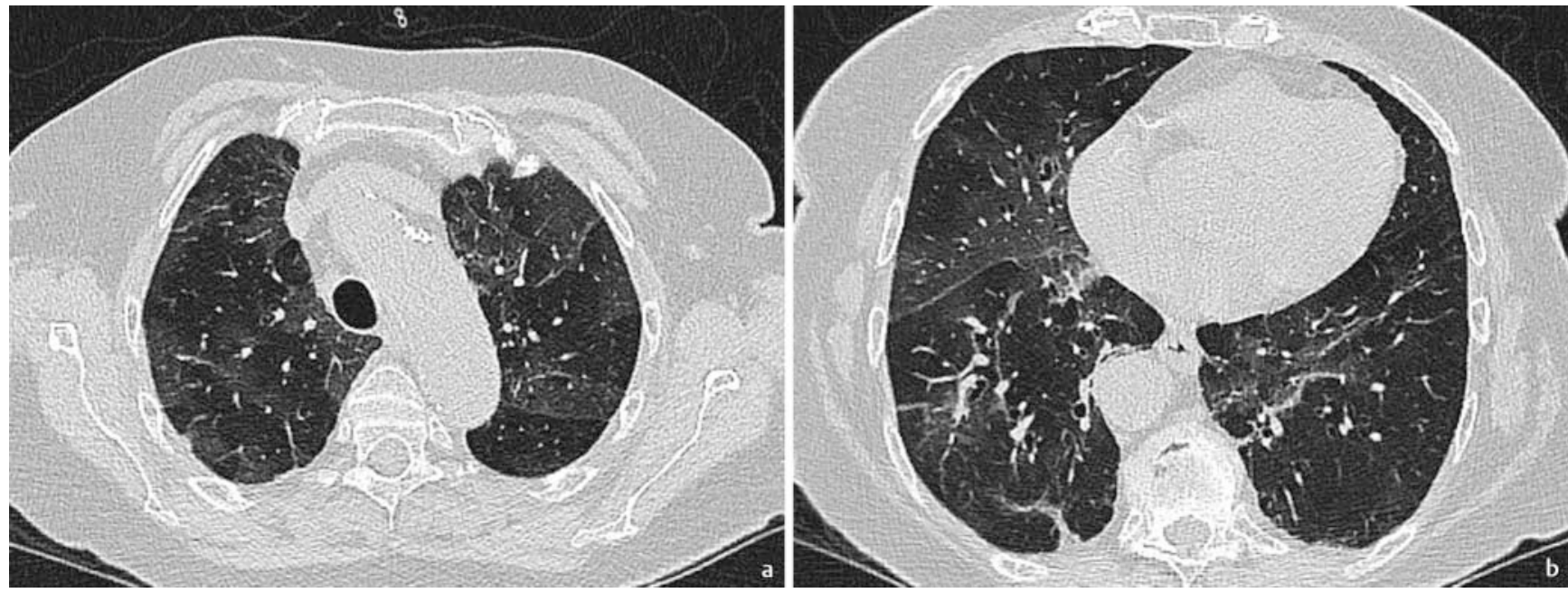

- Fig. 1 Mild COVID-19 pneumonia. 83-year-old female, approx. 24 hours after onset of symptoms: dry cough, weakness, shivering. Peripheral oxygen saturation in room air $87 \%$, respiratory rate $15 / \mathrm{min}$. SARS-CoV-2 RT-PCR from nasal swab performed the same day was positive. CT shows discreet, patchy and geographic, peripheral and perifissural ground-glass opacities bilaterally in all lobes - typical image of mild COVID-19 pneumonia.
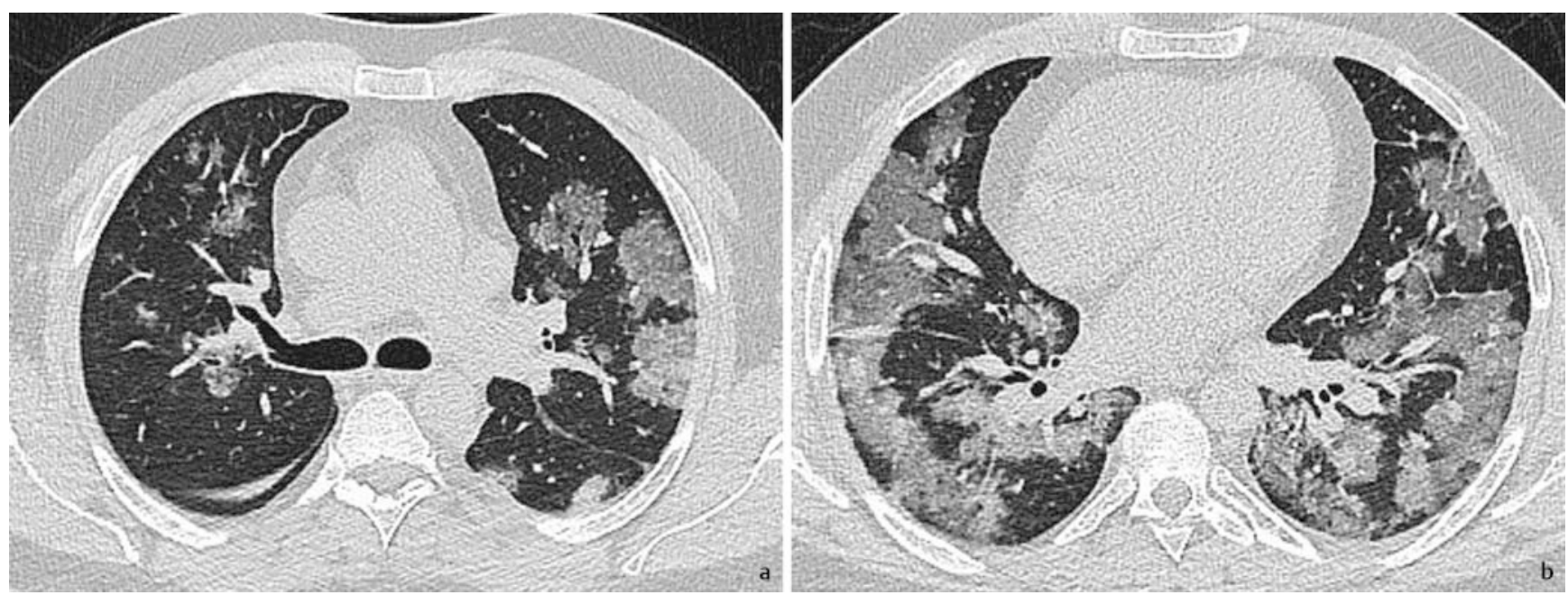

- Fig. 2 Moderate COVID-19 pneumonia. 36-year-old male with laboratory-proven SARS-CoV-2 infection, 5 days after symptom onset: progressive cough and intermittent fever. Peripheral oxygen saturation in room air $94 \%$, respiratory rate $22 / \mathrm{min}$. CT shows extensive, multifocal, bilateral, rounded and geographic ground-glass opacities predominantly in lower lung zones. Note immediate subpleural sparing in both lower lobes.

\section{Pulmonary manifestations}

\section{COVID-19 pneumonia on CT}

Typical signs of COVID-19 pneumonia are rounded, polycyclic, or geographic confluent ground-glass opacities and/or consolidations with peripheral (subpleural and perifissural) or both peripheral and peribronchovascular distribution. The immediate subpleural space can be spared ( $\bullet$ Fig. 1-4) [11-13]. The ratio between groundglass opacities and consolidations varies and ranges from presentations with only ground-glass opacities to presentations with only consolidations [11-13]. At the onset of pneumonia, ground-glass opacities usually dominate, while consolidations increase as the disease progresses [14-18]. In later stages of the disease, consolidations frequently show a band-like or irregular configuration
( $\vee$ Fig. 4). In the recovery phase, ground-glass opacities prevail again [14-18]. COVID-19 pneumonia typically has a multifocal appearance with bilateral lesions in all lobes. Predominant occurrence of changes in the dorsal and basal pulmonary segments is frequently, but not necessarily, seen [11-13]. Further, less common, but highly typical changes include reticular consolidations that - in combination with ground-glass opacities - result in a "crazy paving" pattern ( $\triangleright$ Fig. 3). Moreover, the halo sign and the reversed halo sign (ground glass opacity surrounded by a ring-shaped consolidation) as well as slight dilatation of the vessels in the affected lung areas have been reported [11-13, 19]. In rare cases, the "ring of fire sign" (peripheral ring-shaped opacification consisting of consolidation and ground-glass opacity surrounding lung parenchyma with normal transparency) and the "target sign" (ring-shaped 

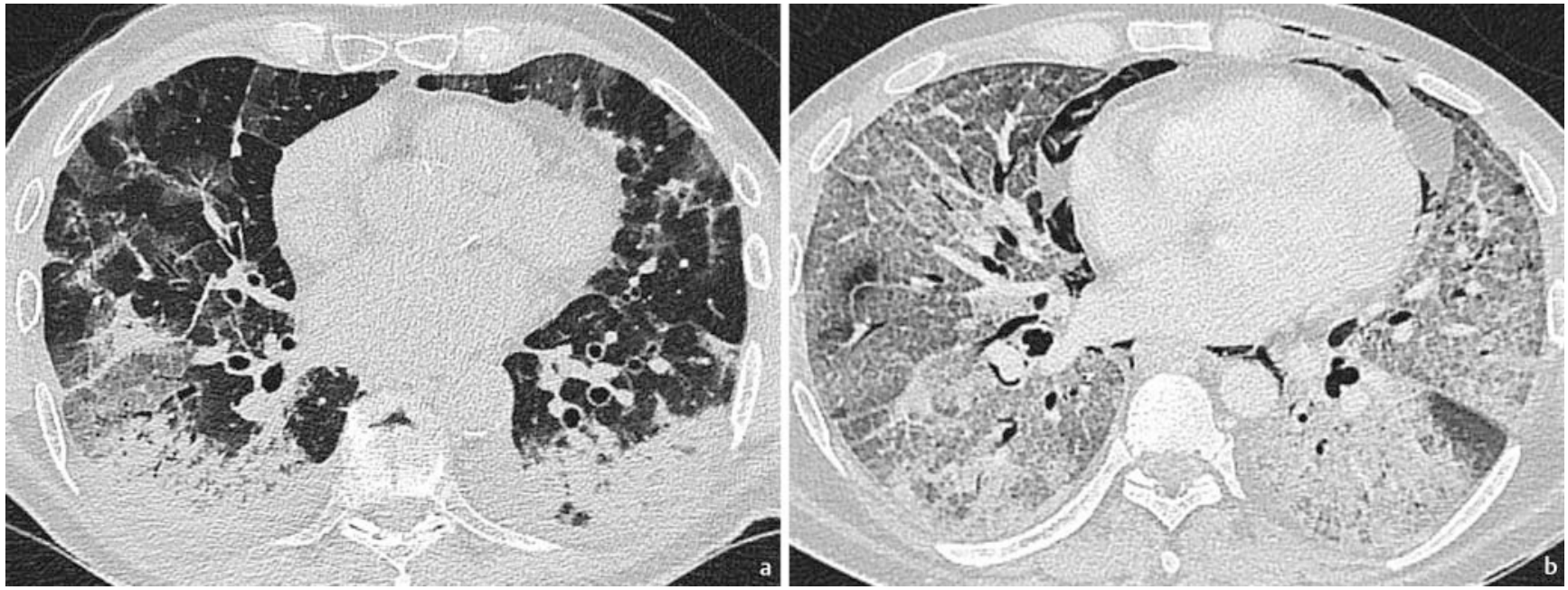

- Fig. 3 Severe COVID-19 pneumonia. a Critically ill 80-year-old male receiving high-flow nasal oxygen, 13 days after onset of symptoms. Combination of confluent multifocal, bilateral, peripheral ground-glass opacities with subtle crazy paving and consolidations, predominantly affecting posterior zones of both lower lobes. Bronchiectasis in both lower lobes and minimal pleural effusion on the left as secondary findings. b Critically ill 33-year-old male receiving high-flow nasal oxygen, 10 days after onset of symptoms. Peripheral oxygen saturation on 10 I $02 /$ min $83 \%$, respiratory rate $28 / \mathrm{min}$. Extensive peripheral and central ground-glass opacities with crazy paving in all lobes bilaterally, most pronounced in lower lung zones. In addition, moderate consolidations in both lower lobes. Pneumomediastinum.
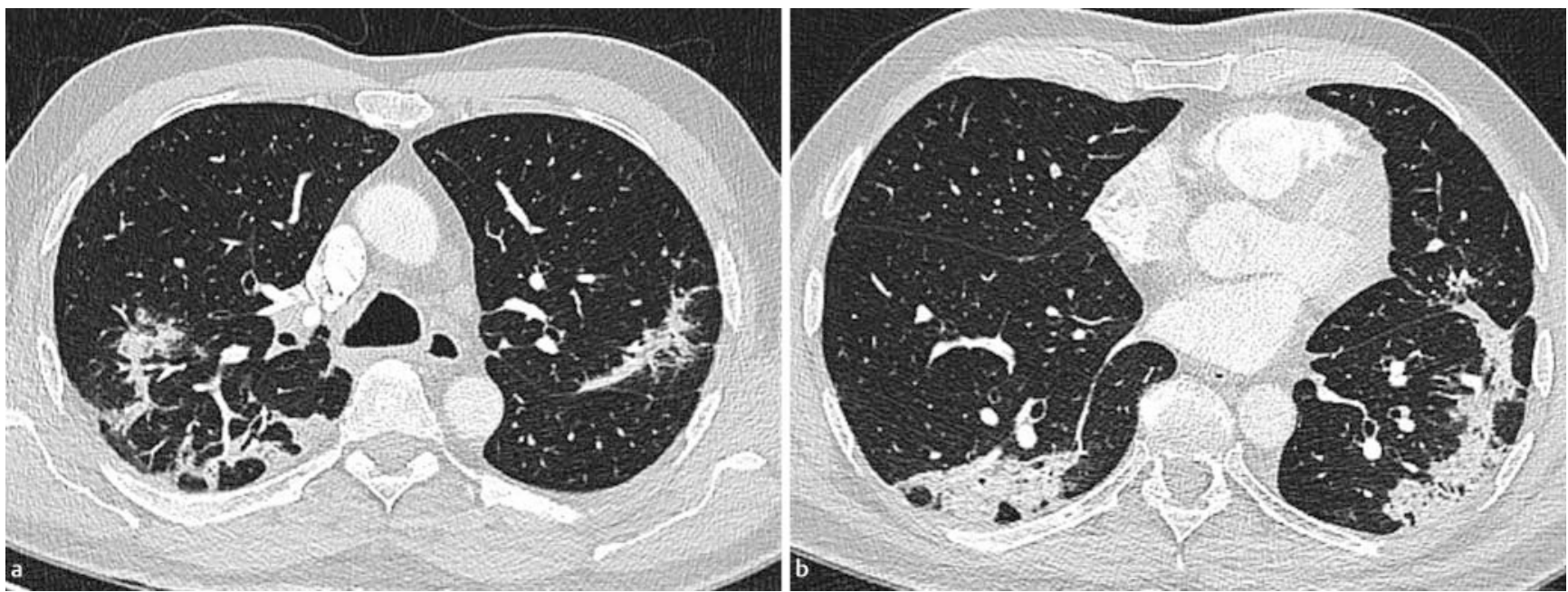

- Fig. 4 Residual changes following COVID-19 pneumonia. 65-year-old male, 3 weeks after recovering from moderate COVID-19 pneumonia without hospitalization. Multifocal bilateral curvilinear parenchymal bands and irregular consolidations, predominantly in posterior lung zones.

opacity around lung parenchyma with normal transparency containing a central hyperdensity reminiscent of a target) have been described as specific imaging findings [20-22].

Solitary lesions, exclusively peribronchovascular distribution of changes, and nodules or cavitations are not typical for COVID-19 pneumonia [11-13]. Pleural effusions accompanied by lymphadenopathy are rare. However, in the case of protracted severe courses, they are slightly more common and may indicate a possible concomitant pathology or complication (see below) [11-13].

Disease severity correlates to a certain degree with the extent of the pulmonary changes on CT [23]. In $10.6 \%$ of symptomatic COVID-19 patients, however, chest CT imaging findings are normal, particularly in the first days of the disease $[11,15]$. On the other hand, typical pulmonary changes can be seen on CT in $54 \%$ of asymptomatic SARS-CoV-2-positive patients [24].

Concomitant pulmonary pathologies like pulmonary emphysema, interstitial lung diseases, fibrotic changes, or pulmonary edema make it difficult to detect typical COVID-19 changes and to discriminate between these and other (e. g., bacterial or viral) forms of pneumonia [11, 25, 26]. Complications of COVID-19 pneumonia like bacterial superinfection (in $10 \%$ of hospitalized patients), acute respiratory distress syndrome (ARDS), pulmonary infarction (due to pulmonary embolism, see below), or cardiac decompensation due to COVID-19 are sometimes difficult to differentiate from pulmonary changes caused directly by SARS-CoV-2 $[11,25,26]$. 


\section{COVID-19 pneumonia on chest X-ray}

The described morphological changes seen on CT can also be identified on chest X-ray $[12,27]$. In the early stages of the disease, the sensitivity is lower (55\% in the first two days after symptom onset) than that of CT ( $88 \%$, performed on average on day 4 after symptom onset) but improves as the disease progresses to $79 \%$ (more than 11 days after symptom onset) while the specificity decreases (from $83 \%$ to $70 \%, p=0.02$ ). Repeating chest X-ray also increases the sensitivity from $73 \%$ to $83 \%$ but reduces the specificity from $80 \%$ to $73 \%[28,29]$. Multifocal (bilateral), primarily peripheral infiltrates should always be considered possible manifestations of COVID-19 pneumonia and a corresponding workup should be initiated, whereas pleural effusions, cavitations, or a pneumothorax make COVID-19 pneumonia less probable. The latter changes in patients with confirmed COVID-19 pneumonia indicate complications [30-32].

\section{COVID-19 pneumonia on thoracic ultrasound}

Ultrasound primarily plays a role as a bedside examination of intensive care patients [12, 33, 34]. Based on B-line artifacts, irregular pleural thickening, and subpleural consolidations, conclusions about the presence and extent of pneumonia can be made $[33,35]$. B-line artifacts are hyperechoic artifacts that are vertical to the surface of the lung and change dynamically as the lung moves, arise from the pleura or consolidated areas of the lung, and resemble a "beam of light" or a "comet tail" $[35,36]$. They correspond to the accumulation of fluid in the pulmonary interstitium and the alveoles and are therefore suitable for identifying even early forms of COVID-19 pneumonia [33, 35]. However, the specificity of these signs is limited [34, 37].

\section{Indications for thoracic imaging}

The indications for thoracic imaging (chest X-ray or CT) in COVID-19 continue to be the object of scientific discussion. The gain of diagnostic information with potential therapeutic consequences comes at the cost of radiation exposure for patients, risk of pathogen transmission to medical personnel and other patients during the examination, and the utilization of personnel, space, and diagnostic and material resources (e. g., personal protective equipment) [38]. The knowledge that is gained relates to multiple areas:

1. Diagnosis: Early publications on the diagnostic performance of chest CT show a pooled sensitivity of $94.6 \%$ (95\% Cl: $91.9 \%$, $96.4 \%$ ) and a pooled specificity of $46.0 \%$ (95\% Cl: $31.9 \%$, $60.7 \%$ ) in the detection of COVID-19. Subsequent studies with up to 4824 patients achieved higher specificities (between $73 \%$ and $94 \%$ ) with an approximately equivalent sensitivity (between $86 \%$ and $90 \%$ ) in relation to the results of reverse transcriptase-polymerase chain reaction (RT-PCR) as the diagnostic reference standard, usually using structured reporting (see below) [13, 39-43]. When using a reference standard composed of RT-PCR results and clinical evaluation, the sensitivity of chest CT was $94.7 \%$ and the specificity was $91.4 \%$ [44]. A suggestive appearance on CT often results in RT-PCR testing being repeated in initially (false) SARS-CoV-2-negative patients who are ultimately positive [39, 43, 45, 46]. COVID-19 cannot be reliably ruled out - particularly in asymptomatic patients based on chest CT which makes it unsuitable for screening [11, 41, 47].

2. Differentiation from alternative diagnoses and detection of concomitant pathologies: Thoracic imaging allows quick detection of additional or alternative pulmonary pathologies like bacterial pneumonias, decompensated cardiac insufficiency, pulmonary embolisms, or tuberculosis. These diseases require specific treatment and their swift diagnosis (prior to a negative RT-PCR result) not only accelerates improvement of the patient but also shortens the patient's stay at an emergency department, hospital, or intensive care unit [38, 39].

3. Detecting complications: Thoracic imaging, particularly CT imaging, enables the detection of pulmonary complications (bacterial superinfection, ARDS, pulmonary infarction, cardiac decompensation, see above) as well as vascular and extrapulmonary manifestations of COVID-19, primarily pulmonary embolisms (see below) [25, 38].

4. Evaluation of severity, baseline for follow-up examinations, and prognostic information: Imaging data regarding preexisting and concomitant pulmonary diseases as well as the extent of COVID-19-associated pulmonary changes is useful for the evaluation of COVID-19 severity, facilitates the evaluation of follow-up examinations, and can be used for prognostic classification $[25,38,48]$. Standardized scores make it possible to objectively evaluate disease severity based on imaging but have not yet become established in practice [23, 48, 49]. The use of automated prediction algorithms for diagnosing and determining the prognosis of COVID-19 is currently not recommended in the clinical routine $[23,49,50]$.

National and international societies including the Thoracic Imaging Working Group of the German Radiological Society and the Fleischner Society do not recommend thoracic imaging either as a screening test for asymptomatic persons or as routine imaging for patients with minimal COVID-19-typical symptoms (except in the case of an increased risk for rapid disease progression): Given sufficient and quick availability, RT-PCR should be given preference here [34, 38, 51-53]. However, this was not always the case in different phases of the pandemic, and it often took multiple days to obtain RT-PCR results. A typical CT examination in such situations provides an almost immediate preliminary diagnosis and makes it possible to rule out other differential diagnoses with corresponding implications including patient isolation $[38,53]$.

Thoracic imaging is recommended in the case of moderate to severe disease with typical COVID-19 symptoms (regardless of the availability of an RT-PCR test result), in the case of worsening of the respiratory situation of SARS-CoV-2-positive patients, and in the case of a discrepancy between a negative RT-PCT test and high clinical suspicion of COVID-19 [38, 51-53].

While the afore-mentioned recommendations of the national societies primarily relate to the use of chest $\mathrm{CT}$, the consensus declaration of the Fleischner Society and the recommendations of the WHO do not specify which modality is to be selected for thoracic imaging $[34,38,51-53]$. Particularly in early stages of the disease, CT has higher sensitivity regarding the detection of 
characteristic pulmonary changes. It is also superior with respect to the detection of alternative diagnoses and complications. As a result of earlier and more precise diagnosis, the length of stay of patients in the corresponding functional areas, the emergency department, and in the hospital can potentially be shortened, thereby reducing the risk of transmission of the virus [38]. However, chest $X$-ray is more quickly available in most cases and is associated with less radiation exposure. Moreover, the use of mobile X-ray units makes it possible to avoid transporting the patient, thereby lowering the infection risk [38]. In the case of repeated examinations and advanced disease stages, the sensitivity of chest X-ray is close to that of CT (see above) [28, 29]. The decision between X-ray and CT as the primary imaging method for COVID-19 patients ultimately depends on the local situation and expertise, individual patient-related factors, and the epidemiological situation $[38,54,55]$. The authors have had success with the early use of chest CT when indicated.

\section{CT examination technique}

Non-contrast, low-dose chest CT examinations should be used for diagnosing COVID-19 unless contrast agent is required for differential diagnoses (e. g., pulmonary embolism) [51, 53].

\section{Structured reporting}

Structured reporting allows simple and concise communication of findings, thereby facilitating clear diagnosis and treatment planning $[56,57]$.

The Radiological Society of North America (RSNA) recommends the use of a four-category system (typical, indifferent, atypical, no pneumonia) for interpreting chest CT examinations with respect to COVID-19. The German Radiological Society has adopted a similar system $[51,58]$. In two studies, the system showed moderate to significant agreement between different observers. However, a not negligible number of SARS-CoV-2-positive patients were classified as "atypical" and "no pneumonia" $[59,60]$.

Another system is the CO-RADS (COVID-19 Reporting and Data System), which was developed by the Dutch Radiological Society (Nederlandse Vereniging voor Radiologie). On a 5-point scale based on existing "RADS" like BI-RADS, the probability of COVID-19 pneumonia is rated on a scale of 1 (highly unlikely) to 5 (highly likely). CO-RADS category 6 indicates a SARS-CoV-2 infection already confirmed by RT-PCR, and CO-RADS category 0 is assigned in the case of incomplete or insufficient image quality $[13,61]$. Using CO-RADS for the diagnosis of COVID-19, various groups achieved a sensitivity between $86 \%$ and $95 \%$ and a specificity between $73 \%$ and $94 \%[13,39-41,44]$.

Based on the authors' experience, CO-RADS is extremely useful in the clinical routine since it uses a clear and intuitive scale with increasing probability for COVID-19 pneumonia and has a high level of acceptance among referring colleagues.

\section{Extrapulmonary manifestations}

\section{Vascular (thromboembolic)}

COVID-19 patients have a greater risk of thromboembolic complications like deep vein thrombosis (DVT) and pulmonary embolism $(P E)$ as well as arterial events like ischemic stroke, myocardial infarction, and systemic arterial embolism [9, 12, 62].

Data regarding the frequency of DVT and PE are relatively heterogeneous and at times contradictory with respect to whether intensive care patients are affected to a greater degree [62]. In 16507 COVID-19 patients, a current meta-analysis shows a prevalence of venous thromboembolism of $14.7 \%$ (95\% Cl: $12.1-$ $17.6 \%)$ : PE occurred in $7.8 \%$ (95\% Cl: 6.2-9.4\%) and DVT in $11.2 \%$ (95\% Cl: $8.4-14.3 \%$ ) of patients [62]. Venous thromboembolisms were significantly more common in patients requiring intensive care compared to those not requiring intensive care (23.2\%, 95\% Cl 17.5-29.6\%, versus 9.0\%, $95 \%$ Cl 6.9-11.4\%; $\mathrm{p}<0.0001)$ and in studies with systematic screening compared to studies in which only symptomatic patients were examined (25.2\% versus $12.7 \%, p=0.04$ ) [62].

According to current meta-analyses, ischemic stroke occurred in 1.1-1.6\% of SARS-CoV-2-positive patients. The risk is elevated compared to non-infected control patients [62, 63]. In most cases, these strokes were classified as cryptogenic. However, it must be added as a limitation that a complete diagnostic workup was often not performed $[63,64]$. In particular, the possibility of paradoxical embolisms due to a persistent foramen ovale has often not been sufficiently clarified but is of particular interest in light of the increase in venous thromboembolisms seen in COVID-19 [65]. In addition to hypercoagulation, vasculitic processes and SARS-CoV-2-induced cardiomyopathy are also involved in the pathogenesis of COVID-19-associated ischemic stroke [66].

According to a current meta-analysis, acute myocardial infarction or an acute coronary syndrome occurs in $1.1 \%$ of patients with COVID-19 [62]. The risk seems elevated during the disease [67]. An (at least partial) specific pathogenetic relationship with the SARS-CoV-2 infection can be presumed based on experience with other viral diseases like SARS and influenza and based on the systemic prothrombotic and hyperinflammatory changes $[67,68]$.

There are a number of case reports regarding acute mesenteric ischemia in COVID-19 [69]. In a study including 412 SARS-CoV-2positive patients, bowel wall changes (usually bowel wall thickening) were seen in $31 \%$ of performed CTs and pneumatosis intestinalis or gas inclusions in the portal venous system were seen in $20 \%$ of CTs in intensive care patients [70]. Although an arterial occlusion could not be detected on imaging in any of these patients, an ischemic cause was confirmed intraoperatively or histologically in the majority of cases. Occlusions of small vessels, non-occlusive ischemia, and additional direct toxic effects of the virus may have pathophysiological effects [70]. In a further study including 141 SARS-CoV-2-positive patients, abnormalities were seen on abdominal CT in 80 (57\%) patients, including 14 (18\% of the abnormal CT examinations) organ infarctions and vascular occlusions but no clear cases of mesenteric ischemia [71]. 
Multiple publications report acute limb ischemia in patients with laboratory-confirmed COVID-19 [72]. It is noteworthy that many of these patients did not have preexisting peripheral arterial occlusive disease and limb ischemia occurred in spite of thrombosis prophylaxis [72]. Some authors additionally report a higher incidence or greater severity of acute limb ischemia during the COVID-19 pandemic compared to the corresponding period in the previous year $[73,74]$.

\section{Extrapulmonary organ manifestations}

SARS-CoV-2 can affect a wide range of additional organs and result in changes that are usually nonspecific on imaging. Abnormalities were seen in $34 \%$ to $56 \%$ of patients with acute or subacute COVID-19 who underwent neuroimaging [75, 76]. Ischemic stroke was most common (see above) [76, 77]. Further common imaging findings were 1) signal alterations in the medial temporal lobe as a result of encephalitis; 2) multifocal, non-confluent, hyperintense white matter lesions on fluid-attenuated inversion recovery (FLAIR) images and diffusion-weighted sequences with variable enhancement and possible associated hemorrhagic lesions (similar to acute disseminated encephalomyelitis ( $\triangleright$ Fig. 5a) and 3) extensive and isolated white matter microhemorrhages ( $\triangleright$ Fig. 5b) [78]. Moreover, leptomeningeal contrast enhancement and extensive and confluent white matter FLAIR hyperintensities without associated hemorrhagic lesions have been described [75, 76, 78].

Myocardial manifestations are seen in severe cases of COVID-19 and contribute to the mortality of the disease, particularly in patients with preexisting cardiac diseases [9, 79, 80]. Ischemic (see above) as well as inflammatory processes seem to play a decisive role $[9,68,81]$. In a meta-analysis including 26 studies with a total of 11685 patients, the weighted pooled prevalence of myocardial damage was $20 \%$ (95\% Cl: $17-23 \%)$. In the individual studies, the prevalence fluctuated between $5 \%$ and $38 \%$ [82]. Multiple case reports show acute myocarditis in patients with active COVID-19 [82]. In the case of hospitalized COVID-19 patients with elevated troponin levels and no other identifiable cause, myocardial damage could be detected on cardiac MRI in $69 \%$ of these patients one month after discharge [83]. In a further study, even unselected patients who had recovered from COVID-19 still showed signs of cardiac involvement (78\%) or active myocardial inflammation (60\%) on MRI approximately 70 days after recovery - regardless of preexisting conditions, disease severity, and time to initial diagnosis [84].

Apart from the lung, the liver is the organ most commonly affected by COVID-19 [85]. However, the changes visible on imaging are usually only subtle and nonspecific. Among other things, periportal edema and heterogeneity of the liver parenchyma indicate SARS-CoV-2-induced hepatitis [70, 71, 85]. A distended gallbladder filled with sludge and enlarged intrahepatic bile ducts are also often observed and indicate impaired bile drainage without a mechanical obstruction. This can result in cholecystitis $[70,71,85]$. Hepatic steatosis is considered an independent risk factor for severe COVID-19 [85].

If not of an ischemic origin (see above), involvement of the gastrointestinal tract is the result of viral gastroenteritis and is seen in the form of typically hypodense thickening of the intestinal wall $[70,85]$. It can mostly be attributed to submucosal edema and is sometimes accompanied by hyperenhancement of the mucosa, moderate distension and fluid filling of the affected bowel loops, and inflammatory changes in the surrounding fat tissue $[70,85]$.

Moreover, in addition to the already mentioned organ infarctions (see above), COVID-19-associated changes have been described in the pancreas (pancreatitis), the kidney (heterogeneity, loss of corticomedullary differentiation), and urinary system (diffuse irregularity and thickening of the wall of the bladder due to interstitial or hemorrhagic cystitis), the spleen (splenomegaly), the musculoskeletal system, the eyes, and the skin [85]. Since providing a detailed description of these changes exceeds the scope of this overview, please refer to the relevant specialized literature.

\section{COVID-19 in children}

Children contract COVID-19 significantly less frequently and generally experience a milder disease course compared to adults $[85,86]$. Nevertheless, approximately one third of children hospitalized with COVID-19 require intensive care and individual cases have been fatal, particularly in children with preexisting conditions [85, 86]. In addition, pediatric multisystem inflammatory syndrome (PIMS), a presumably autoimmune-mediated hyperinflammatory response with parallels to atypical Kawasaki disease, occurs in rare cases in children after acute COVID-19 disease [85, 87]. Since providing a detailed description of the pediatric aspects of COVID-19 is beyond the scope of this study, please refer to the specialized literature for more information.

\section{Long-term effects of COVID-19 (long COVID)}

To date, only minimal data regarding the long-term effects of COVID-19 is available. Abnormalities, usually ground-glass opacities followed by irregular lines, were seen on chest CT 6 months after discharge in approximately half of 353 patients hospitalized due to COVID-19 [88]. Another publication describes fibrosis-like changes in $35 \%$ of cases and residual ground glass opacity or interstitial consolidations in $27 \%$ of 114 patients 6 months after severe COVID-19 pneumonia [89]. Further studies with larger patient numbers and longer observation periods are needed to better evaluate the possible long-term effects of COVID-19.

\section{Risk of COVID-19 for personnel in radiology}

Employees in radiology departments are at an increased risk of SARS-CoV-2 infection, similar to those working in intensive care units and dedicated COVID-19 units [90]. Due to the limited scope of this overview, please refer to the relevant specialized literature for more detailed information regarding these risks and possible protective measures. 

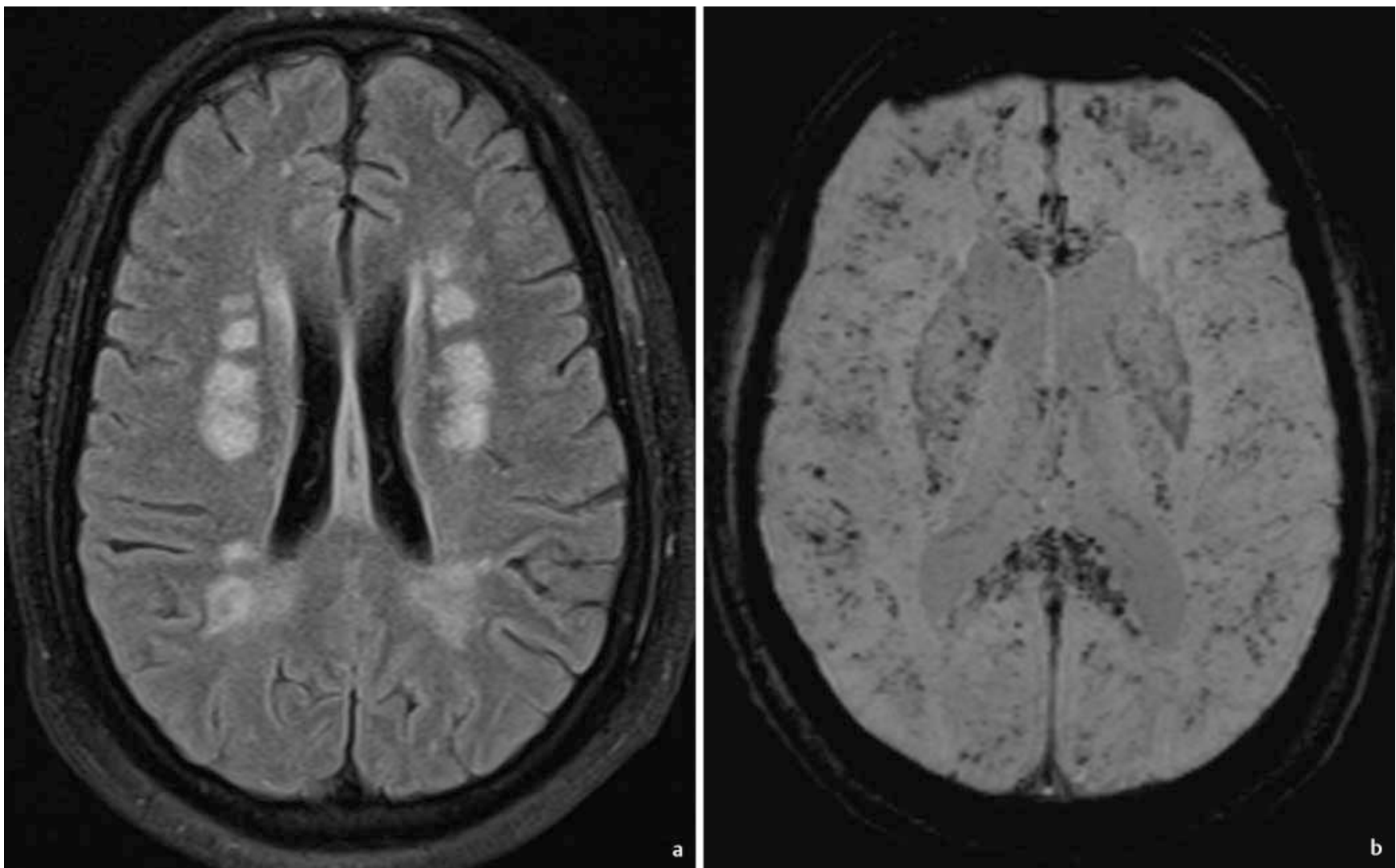

- Fig. 5 Cerebral manifestations of COVID-19. a Transverse FLAIR (Fluid Attenuated Inversion Recovery). Patchy, non-confluent, T2-hyperintense white matter lesions, corresponding to inflammatory demyelinating changes (similar to acute disseminated encephalomyelitis - ADEM). b Transversal SWI (Susceptibility-Weighted Imaging). Pronounced disseminated white matter microhemorrhages involving the corpus callosum. Both figures (a, b): courtesy of Prof. Dr. H. Rolf Jäger, Neuroradiological Academic Unit, UCL Queen Square Institute of Neurology, London, UK.

\section{Conclusion}

COVID-19 results in typical findings in the lung that can be visualized most effectively with CT. In the case of quickly available RT-PCR test results, the purpose of radiological imaging is not primary diagnosis but rather differentiation from other diseases, investigation of unclear cases with discrepancies between clinical suspicion and RT-PCR test results, evaluation of severity, and detection of comorbidities and complications. Thromboembolic events, particularly venous thromboembolisms as well as arterial vascular occlusions with resulting infarctions in the corresponding target organs, are the most common extrapulmonary complications of COVID-19. Knowledge of additional extrapulmonary organ manifestations is helpful for management particularly of critically ill patients with a protracted course who require intensive care. The possible long-term effects of COVID-19 are only known to a minimal extent and require longer and more detailed observation.

\section{Conflict of Interest}

The authors declare that they have no conflict of interest.
References

[1] World Health Organization (WHO). WHO Coronavirus Disease (COVID-19) Dashboard. Im Internet (Stand: 02.05.2021): https://covid19.who.int

[2] Robert-Koch-Institut (RKI). Aktueller Lage-/Situationsbericht des RKI zU COVID-19. Im Internet (Stand: 02.05.2021): https://www.rki.de/DE/Con tent/InfAZ/N/Neuartiges_Coronavirus/Situationsberichte/Gesamt.html

[3] Cevik M, Kuppalli K, Kindrachuk J et al. Virology, transmission, and pathogenesis of SARS-CoV-2. BM] 2020; 371: m3862 doi:10.1136/bmj.m3862

[4] van Doremalen N, Bushmaker T, Morris DH et al. Aerosol and Surface Stability of SARS-CoV-2 as Compared with SARS-CoV-1. N Engl J Med 2020; 382: 1564-1567. doi:10.1056/NEJMc2004973

[5] Zhu J, Ji P, Pang J et al. Clinical characteristics of 3062 COVID-19 patients: A meta-analysis. J Med Virol 2020; 92: 1902-1914. doi:10.1002/ jmv. 25884

[6] Agyeman AA, Chin KL, Landersdorfer CB et al. Smell and Taste Dysfunction in Patients With COVID-19: A Systematic Review and Meta-analysis. Mayo Clin Proc 2020; 95: 1621-1631. doi:10.1016/j. mayocp.2020.05.030

[7] Pfeifer M, Hamer OW. [COVID-19 pneumonia]. Gastroenterologe 2020: 1-11. doi:10.1007/s11377-020-00488-x

[8] Salje H, Tran Kiem C, Lefrancq $N$ et al. Estimating the burden of SARS-CoV-2 in France. Science 2020; 369: 208-211. doi:10.1126| science.abc3517

[9] Gupta A, Madhavan MV, Sehgal K et al. Extrapulmonary manifestations of COVID-19. Nat Med 2020; 26: 1017-1032. doi:10.1038/s41591-0200968-3 
[10] Ackermann M, Verleden SE, Kuehnel M et al. Pulmonary Vascular Endothelialitis, Thrombosis, and Angiogenesis in Covid-19. N Engl J Med 2020; 383: 120-128. doi:10.1056/NEJMoa2015432

[11] Adams HJA, Kwee TC, Yakar D et al. Chest CT Imaging Signature of Coronavirus Disease 2019 Infection: In Pursuit of the Scientific Evidence. Chest 2020; 158: 1885-1895. doi:10.1016/j.chest.2020.06.025

[12] Revzin MV, Raza S, Warshawsky R et al. Multisystem Imaging Manifestations of COVID-19, Part 1: Viral Pathogenesis and Pulmonary and Vascular System Complications. Radiographics 2020; 40: 1574-1599. doi:10.1148/rg.2020200149

[13] Prokop M, van Everdingen W, van Rees Vellinga T et al. CO-RADS A categorical CT assessment scheme for patients with suspected COVID-19: definition and evaluation. Radiology 2020: 201473 doi:10.1148/radiol.2020201473

[14] Wang Y, Dong C, Hu Y et al. Temporal Changes of CT Findings in 90 Patients with COVID-19 Pneumonia: A Longitudinal Study. Radiology 2020; 296: E55-E64. doi:10.1148/radiol.2020200843

[15] Ding X, Xu J, Zhou J et al. Chest CT findings of COVID-19 pneumonia by duration of symptoms. Eur J Radiol 2020; 127: 109009 doi:10.1016/ j.ejrad.2020.109009

[16] Bernheim A, Mei X, Huang M et al. Chest CT Findings in Coronavirus Disease-19 (COVID-19): Relationship to Duration of Infection. Radiology 2020: 200463 doi:10.1148/radiol.2020200463

[17] Pan F, Ye T, Sun P et al. Time Course of Lung Changes On Chest CT During Recovery From 2019 Novel Coronavirus (COVID-19) Pneumonia. Radiology 2020: 200370 doi:10.1148/radiol.2020200370

[18] Pan Y, Guan H, Zhou S et al. Initial CT findings and temporal changes in patients with the novel coronavirus pneumonia (2019-nCoV): a study of 63 patients in Wuhan, China. Eur Radiol 2020; 30: 3306-3309. doi:10.1007/s00330-020-06731-x

[19] Wormanns D, Hamer OW. [Glossary of Terms for Thoracic ImagingGerman Version of the Fleischner Society Recommendations]. Rofo 2015; 187: 638-661. doi:10.1055/s-0035-1553216

[20] Piyavisetpat N, Pongpirul K, Sukkasem W et al. 'Ring of fire' appearance in COVID-19 pneumonia. BMJ Case Rep 2020; 13: doi:10.1136/bcr2020-236167

[21] Müller CIS, Müller NL. Chest CT target sign in a couple with COVID-19 pneumonia. Radiol Bras 2020; 53: 252-254. doi:10.1590/01003984.2020.0089

[22] Jafari R, Maghsoudi H, Saburi A. A Unique Feature of COVID-19 Infection in Chest CT; "Pulmonary Target" Appearance. Acad Radiol 2021; 28: 146-147. doi:10.1016/j.acra.2020.11.004

[23] Yang R, Li X, Liu H et al. Chest CT Severity Score: An Imaging Tool for Assessing Severe COVID-19. Radiol Cardiothorac Imaging 2020; 2: doi:10.1148/ryct.2020200047

[24] Inui S, Fujikawa A, Jitsu M et al. Chest CT Findings in Cases from the Cruise Ship "Diamond Princess" with Coronavirus Disease 2019 (COVID-19). Radiol Cardiothorac Imaging 2020; 2: e200110 doi:10.1148/ryct.2020200110

[25] Kwee TC, Kwee RM. Chest CT in COVID-19: What the Radiologist Needs to Know. Radiographics 2020; 40: 1848-1865. doi:10.1148/rg.2020200159

[26] Duzgun SA, Durhan G, Demirkazik FB et al. COVID-19 pneumonia: the great radiological mimicker. Insights Imaging 2020; 11: 118 doi:10.1186/s13244-020-00933-z

[27] Wong HYF, Lam HYS, Fong AH-T et al. Frequency and Distribution of Chest Radiographic Findings in Patients Positive for COVID-19. Radiology 2020; 296: E72-E78. doi:10.1148/radiol.2020201160

[28] Cleverley J, Piper J, Jones MM. The role of chest radiography in confirming covid-19 pneumonia. BM] 2020; 370: m2426 doi:10.1136/ bmj.m2426
[29] Stephanie S, Shum T, Cleveland H et al. Determinants of Chest X-Ray Sensitivity for COVID- 19: A Multi-Institutional Study in the United States. Radiol Cardiothorac Imaging 2020; 2: doi:10.1148/ ryct.2020200337

[30] Kanne JP, Little BP, Chung JH et al. Essentials for Radiologists on COVID-19: An Update-Radiology Scientific Expert Panel. Radiology 2020; 296: E113-E114. doi:10.1148/radiol.2020200527

[31] Jacobi A, Chung M, Bernheim A et al. Portable chest X-ray in coronavirus disease-19 (COVID-19): A pictorial review. Clin Imaging 2020; 64: 3542. doi:10.1016/j.clinimag.2020.04.001

[32] Salehi S, Abedi A, Balakrishnan S et al. Coronavirus Disease 2019 (COVID-19): A Systematic Review of Imaging Findings in 919 Patients. Am J Roentgenol 2020; 215: 87-93. doi:10.2214/Am J Roentgenol.20.23034

[33] Soldati G, Smargiassi A, Inchingolo R et al. Is There a Role for Lung Ultrasound During the COVID-19 Pandemic? J Ultrasound Med Off J Am Inst Ultrasound Med 2020; 39: 1459-1462. doi:10.1002/jum.15284

[34] Revel M-P, Parkar AP, Prosch H et al. COVID-19 patients and the radiology department - advice from the European Society of Radiology (ESR) and the European Society of Thoracic Imaging (ESTI). Eur Radiol 2020. doi:10.1007/s00330-020-06865-y

[35] Volpicelli G, Gargani L. Sonographic signs and patterns of COVID-19 pneumonia. Ultrasound J 2020; 12: 22 doi:10.1186/s13089-020-00171-w

[36] Vetrugno L, Bove T, Orso D et al. Our Italian experience using lung ultrasound for identification, grading and serial follow-up of severity of lung involvement for management of patients with COVID-19. Echocardiography 2020; 37: 625-627. doi:10.1111/echo.14664

[37] Vetrugno L, Bove T, Orso D et al. Lung Ultrasound and the COVID-19 "Pattern": Not All That Glitters Today Is Gold Tomorrow. J Ultrasound Med 2020; 39: 2281-2282. doi:10.1002/jum. 15327

[38] Rubin GD, Ryerson C], Haramati LB et al. The Role of Chest Imaging in Patient Management during the COVID-19 Pandemic: A Multinational Consensus Statement from the Fleischner Society. Chest 2020. doi:10.1016/j.chest.2020.04.003

[39] Gross A, Heine G, Schwarz M et al. Structured reporting of chest CT provides high sensitivity and specificity for early diagnosis of COVID-19 in a clinical routine setting. Br J Radiol 2021; 94: 20200574 doi:10.1259/ bjr.20200574

[40] Schalekamp S, Bleeker-Rovers CP, Beenen LFM et al. Chest CT in the Emergency Department for Diagnosis of COVID-19 Pneumonia: Dutch Experience. Radiology 2020. doi:10.1148/radiol.2020203465

[41] De Smet K, De Smet D, Ryckaert T et al. Diagnostic Performance of Chest CT for SARS-CoV-2 Infection in Individuals with or without COVID-19 Symptoms. Radiology 2021; 298: E30-E37. doi:10.1148/ radiol.2020202708

[42] Dangis A, Gieraerts C, Bruecker YD et al. Accuracy and reproducibility of low-dose submillisievert chest CT for the diagnosis of COVID-19. Radiol Cardiothorac Imaging 2020; 2: e200196 doi:10.1148/ryct.2020200196

[43] Herpe G, Lederlin M, Naudin M et al. Efficacy of Chest CT for COVID-19 Pneumonia in France. Radiology 2020: 202568 doi:10.1148/radiol.2020202568

[44] Schulze-Hagen M, Hübel C, Meier-Schroers M et al. Low-Dose Chest CT for the Diagnosis of COVID-19-A Systematic, Prospective Comparison With PCR. Dtsch Arzteblatt Int 2020; 117: 389-395. doi:10.3238/ arztebl.2020.0389

[45] Xie X, Zhong Z, Zhao W et al. Chest CT for Typical 2019-nCoV Pneumonia: Relationship to Negative RT-PCR Testing. Radiology 2020: 200343 doi:10.1148/radiol.2020200343

[46] Huang P, Liu T, Huang L et al. Use of Chest CT in Combination with Negative RT-PCR Assay for the 2019 Novel Coronavirus but High Clinical Suspicion. Radiology 2020; 295: 22-23. doi:10.1148/radiol.2020200330 
[47] Raptis CA, Hammer MM, Short RG et al. Chest CT and Coronavirus Disease (COVID-19): A Critical Review of the Literature to Date. Am J Roentgenol 2020; 215: 839-842. doi:10.2214/Am J Roentgenol.20.23202

[48] Feng Z, Yu Q, Yao S et al. Early prediction of disease progression in COVID-19 pneumonia patients with chest CT and clinical characteristics. Nat Commun 2020; 11: 4968 doi:10.1038/s41467-020-18786-x

[49] Francone M, lafrate F, Masci GM et al. Chest CT score in COVID-19 patients: correlation with disease severity and short-term prognosis. Eur Radiol 2020; 30: 6808-6817. doi:10.1007/s00330-020-07033-y

[50] Wynants L, Van Calster B, Collins GS et al. Prediction models for diagnosis and prognosis of covid-19 infection: systematic review and critical appraisal. BMJ 2020; 369: m1328 doi:10.1136/bmj.m1328

[51] Vogel-Claussen J, Ley-Zaporozhan J, Agarwal P et al. Recommendations of the Thoracic Imaging Section of the German Radiological Society for clinical application of chest imaging and structured CT reporting in the COVID-19 pandemic. Rofo 2020; 192: 633-640. doi:10.1055/a-11748378

[52] American College of Radiology (ACR). ACR Recommendations for the use of Chest Radiography and Computed Tomography (CT) for Suspected COVID-19 Infection (22.03.2020). Im Internet (Stand: 02.05.2021): https://www.acr.org/Advocacy-and-Economics/ACR-Position-State ments/Recommendations-for-Chest-Radiography-and-CT-for-Suspect ed-COVID19-Infection

[53] World Health Organization (WHO). Use of chest imaging in COVID-19 A rapid advice guide (11.06.2020). Im Internet (Stand: 02.05.2021): https://www.who.int/publications-detail-redirect/use-of-chest-ima ging-in-covid-19

[54] Flor N, Dore R, Sardanelli F. On the Role of Chest Radiography and CT in the Coronavirus Disease (COVID-19) Pandemic. Am J Roentgenol 2020; 215: W44 doi:10.2214/Am J Roentgenol.20.23411

[55] Cheng Z, Yan F, Yang W. Reply to "On the Role of Chest Radiography and CT in the Coronavirus Disease (COVID-19) Pandemic". Am J Roentgenol 2020; 215: W45 doi:10.2214/Am J Roentgenol.20.24159

[56] An JY, Unsdorfer KML, Weinreb JC. BI-RADS, C-RADS, CAD-RADS, LI-RADS, Lung-RADS, NI-RADS, O-RADS, PI-RADS, TI-RADS: Reporting and Data Systems. Radiographics 2019; 39: 1435-1436. doi:10.1148/ rg.2019190087

[57] Schwartz LH, Panicek DM, Berk AR et al. Improving communication of diagnostic radiology findings through structured reporting. Radiology 2011; 260: 174-181. doi:10.1148/radiol.11101913

[58] Simpson S, Kay FU, Abbara S et al. Radiological Society of North America Expert Consensus Statement on Reporting Chest CT Findings Related to COVID-19. Endorsed by the Society of Thoracic Radiology, the American College of Radiology, and RSNA. Radiol Cardiothorac Imaging 2020; 2: e200152 doi:10.1148/ryct.2020200152

[59] de Jaegere TMH, Krdzalic J, Fasen BACM et al. Radiological Society of North America Chest CT Classification System for Reporting COVID-19 Pneumonia: Interobserver Variability and Correlation with RT-PCR. Radiol Cardiothorac Imaging 2020; 2: doi:10.1148/ryct.2020200213

[60] Som A, Lang M, Yeung T et al. Implementation of the Radiological Society of North America Expert Consensus Guidelines on Reporting Chest CT Findings Related to COVID-19: A Multireader Performance Study. Radiol Cardiothorac Imaging 2020; 2: doi:10.1148/ ryct.2020200276

[61] Zimmerman M. Handreiking Standaardverslag CT-thorax COVID inclusief CO-RADS en CT score (13.05.2020). Im Internet (Stand: 02.05.2021): https://www.radiologen.nl/secties/netwerk-covid-19/documenten/ handreiking-standaardverslag-ct-thorax-covid-inclusief-co-rads

[62] Tan BK, Mainbourg S, Friggeri A et al. Arterial and venous thromboembolism in COVID-19: a study-level meta-analysis. Thorax 2021. doi:10.1136/thoraxjnl-2020-215383
[63] Katsanos AH, Palaiodimou L, Zand R et al. The Impact of SARS-CoV-2 on Stroke Epidemiology and Care: A Meta-Analysis. Ann Neurol 2021; 89: 380-388. doi:10.1002/ana.25967

[64] Yaghi S, Ishida K, Torres J et al. SARS-CoV-2 and Stroke in a New York Healthcare System. Stroke 2020; 51: 2002-2011. doi:10.1161/ STROKEAHA. 120.030335

[65] Albiero R, Seresini G. Letter by Albiero and Seresini Regarding Article, "SARS-CoV-2 and Stroke in a New York Healthcare System". Stroke 2020; 51: e310-e311. doi:10.1161/STROKEAHA.120.031093

[66] Spence JD, de Freitas GR, Pettigrew LC et al. Mechanisms of Stroke in COVID-19. Cerebrovasc Dis 2020; 49: 451-458. doi:10.1159/ 000509581

[67] Modin D, Claggett B, Sindet-Pedersen C et al. Acute COVID-19 and the Incidence of Ischemic Stroke and Acute Myocardial Infarction. Circulation 2020; 142: 2080-2082. doi:10.1161/CIRCULATIONAHA.120.050809

[68] Kang Y, Chen T, Mui D et al. Cardiovascular manifestations and treatment considerations in COVID-19. Heart 2020; 106: 1132-1141. doi:10.1136/heartjnl-2020-317056

[69] Singh B, Kaur P. COVID-19 and acute mesenteric ischemia: A review of literature. Hematol Transfus Cell Ther 2020. doi:10.1016/j. htct.2020.10.959

[70] Bhayana R, Som A, Li MD et al. Abdominal Imaging Findings in COVID-19: Preliminary Observations. Radiology 2020; 297: E207-E215. doi:10.1148/radiol.2020201908

[71] Goldberg-Stein S, Fink A, Paroder V et al. Abdominopelvic CT findings in patients with novel coronavirus disease 2019 (COVID-19). Abdom Radiol (NY) 2020; 45: 2613-2623. doi:10.1007/s00261-020-02669-2

[72] Avila J, Long B, Holladay D et al. Thrombotic complications of COVID-19. Am J Emerg Med 2021; 39: 213-218. doi:10.1016/j.ajem.2020.09.065

[73] Bellosta R, Luzzani L, Natalini G et al. Acute limb ischemia in patients with COVID-19 pneumonia. J Vasc Surg 2020; 72: 1864-1872. doi:10.1016/j.jvs.2020.04.483

[74] Kashi M, Jacquin A, Dakhil B et al. Severe arterial thrombosis associated with Covid-19 infection. Thromb Res 2020; 192: 75-77. doi:10.1016/ j.thromres.2020.05.025

[75] Egbert AR, Cankurtaran S, Karpiak S. Brain abnormalities in COVID-19 acute/subacute phase: A rapid systematic review. Brain Behav Immun 2020; 89: 543-554. doi:10.1016/j.bbi.2020.07.014

[76] Kremer S, Lersy F, Anheim $M$ et al. Neurologic and neuroimaging findings in patients with COVID-19: A retrospective multicenter study. Neurology 2020; 95: e1868-e1882. doi:10.1212/WNL.0000000000010112

[77] Jain R, Young M, Dogra S et al. COVID-19 related neuroimaging findings: A signal of thromboembolic complications and a strong prognostic marker of poor patient outcome. J Neurol Sci 2020; 414: 116923 doi:10.1016/j.jns.2020.116923

[78] Kremer S, Lersy F, de Sèze ] et al. Brain MRI Findings in Severe COVID-19: A Retrospective Observational Study. Radiology 2020; 297: E242-E251. doi:10.1148/radiol.2020202222

[79] Shi S, Qin M, Shen B et al. Association of Cardiac Injury With Mortality in Hospitalized Patients With COVID-19 in Wuhan, China. JAMA Cardiol 2020; 5: 802-810. doi:10.1001/jamacardio.2020.0950

[80] Guo T, Fan Y, Chen M et al. Cardiovascular Implications of Fatal Outcomes of Patients With Coronavirus Disease 2019 (COVID-19). JAMA Cardiol 2020; 5: 811-818. doi:10.1001/jamacardio.2020.1017

[81] Ruan Q, Yang K, Wang W et al. Clinical predictors of mortality due to COVID-19 based on an analysis of data of 150 patients from Wuhan, China. Intensive Care Med 2020; 46: 846-848. doi:10.1007/s00134020-05991-x

[82] Bavishi C, Bonow RO, Trivedi V et al. Special Article - Acute myocardial injury in patients hospitalized with COVID-19 infection: A review. Prog Cardiovasc Dis 2020; 63: 682-689. doi:10.1016/j.pcad.2020.05.013 
[83] Knight DS, Kotecha T, Razvi Y et al. COVID-19: Myocardial Injury in Survivors. Circulation 2020; 142: 1120-1122. doi:10.1161/ CIRCULATIONAHA.120.049252

[84] Puntmann VO, Carerj ML, Wieters I et al. Outcomes of Cardiovascular Magnetic Resonance Imaging in Patients Recently Recovered From Coronavirus Disease 2019 (COVID-19). JAMA Cardiol 2020; 5: 12651273. doi:10.1001/jamacardio.2020.3557

[85] Revzin MV, Raza S, Srivastava NC et al. Multisystem Imaging Manifestations of COVID-19, Part 2: From Cardiac Complications to Pediatric Manifestations. Radiographics 2020; 40: 1866-1892. doi:10.1148/ rg.2020200195

[86] Kim L, Whitaker M, O’Halloran A et al. Hospitalization Rates and Characteristics of Children Aged $<18$ Years Hospitalized with LaboratoryConfirmed COVID-19 - COVID-NET, 14 States, March 1-july 25, 2020. MMWR Morb Mortal Wkly Rep 2020; 69: 1081-1088. doi:10.15585/ mmwr.mm6932e3
[87] Riphagen S, Gomez X, Gonzalez-Martinez C et al. Hyperinflammatory shock in children during COVID-19 pandemic. Lancet 2020; 395: $1607-$ 1608. doi:10.1016/S0140-6736(20)31094-1

[88] Huang C, Huang L, Wang Y et al. 6-month consequences of COVID-19 in patients discharged from hospital: a cohort study. Lancet 2021; 397: 220-232. doi:10.1016/S0140-6736(20)32656-8

[89] Han X, Fan Y, Alwalid O et al. Six-Month Follow-up Chest CT findings after Severe COVID-19 Pneumonia. Radiology 2021: 203153 doi:10.1148/radiol.2021203153

[90] Finkenzeller T, Lenhart S, Reinwald M et al. Risk to Radiology Staff for Occupational COVID-19 Infection in a High-Risk and a Low-Risk Region in Germany: Lessons from the "First Wave". Rofo 2021. doi:10.1055/ a-1393-6668 